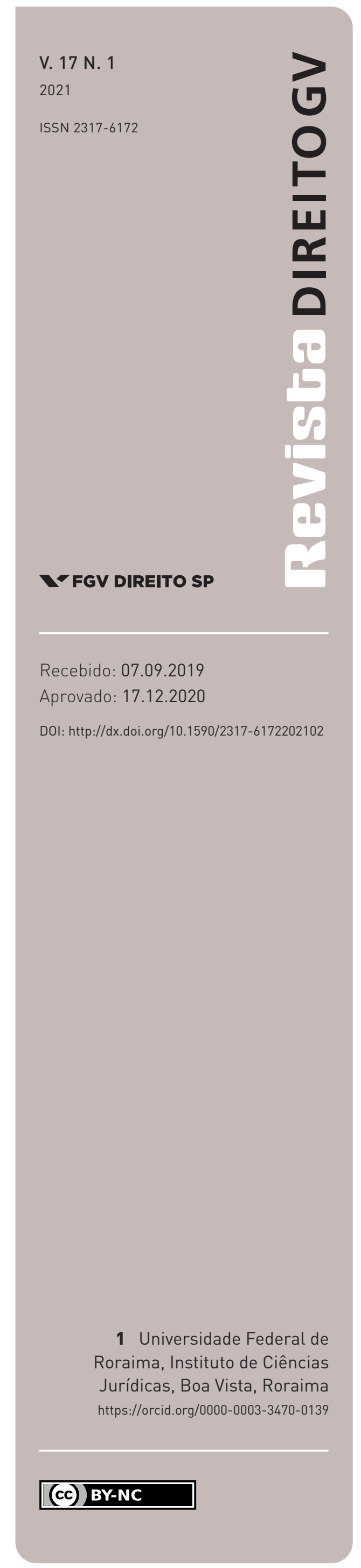

\section{A INTERIORIZAÇÃO COMO UM DIREITO SOCIAL UNIVERSALIZÁVEL}

\author{
“INTERIORIZATION" AS A UNIVERSALIZABLE SOCIAL RIGHT
}

Fernando César Costa Xavier ${ }^{1}$

\section{Resumo}

0 artigo recorda que a lei brasileira, para atender aos desafios político-administrativos surgidos com a crise migratória de venezuelanos no estado de Roraima, passou a reconhecer a "interiorização" como um direito de mobilidade, que deveria ser implementado como medida ampliativa de "assistência emergencial para acolhimento a pessoas em situação de vulnerabilidade decorrente de fluxo migratório provocado por crise humanitária", nos termos do art. 50, X, da Lei n. 13.684/2018. 0 método empregado examina o conjunto de leis aplicáveis le os princípios nelas subjacentes) e o interpreta tanto sistematicamente, buscando suplantar inconsistências e incoerências, quanto literalmente, dando contornos rigorosos às definições utilizadas nas normas. A partir disso, a tese desenvolvida é de que esse direito de interiorização, conforme disposto na lei, poderia ser vindicável por qualquer sujeito (estrangeiro migrante ou nacional) e em qualquer situação de crise humanitária Iprovocada por processos migratórios internacionais ou internos ou outras situações de deslocamento descontrolado). A ampliação de sua incidência não frustraria, mas antes promoveria os propósitos últimos que mobilizaram a formulação da política de interiorização, a saber, os de aliviar a pressão do incremento demográfico sobre o sistema público de seguridade social e o de possibilitar a inserção laboral do excedente populacional em outras regiões do país. Mais que um direito migratório, seria a interiorização um direito social, devendo por isso se ajustar aos princípios da universalidade e da progressividade.

\section{Palavras-chave}

Interiorização; direitos sociais; universalidade; migração venezuelana; Roraima.

\begin{abstract}
The article argues that Brazilian law, in order to address the political and administrative challenges arising from the Venezuelan migration crisis in the State of Roraima, came to recognize "internalization" as a right of mobility, which would be implemented as an expansive measure of "emergency assistance to welcome people in situations of vulnerability due to migration flow caused by humanitarian crisis", pursuant to article 5, X, of Law 13.684/2018. The applied method examines the set of relevant norms (and its underlying principles) and interprets it both systematically, seeking to overcome inconsistencies and incoherences, and literally, giving rigorous contours to the definitions used in the norms. From this, the developed thesis is that this right of internalization, as provided by that Law, could be vindicated by any subject (migrant/foreigner or national) and in any situation of humanitarian crisis (caused by international or internal migratory processes, or other situations of uncontrolled displacement). Increasing its incidence would not frustrate, but rather promote the ultimate purposes that mobilized the formulation of the policy of internalization, namely to alleviate the pressure of demographic increase on the public social security system and to enable the insertion of the surplus into the workplace population in other regions of the country. More than a migratory right, internalization would be a social right, and must therefore conform to the principles of universality and progressivity.
\end{abstract}




\section{INTRODUÇÃO}

No início de 2018, a Força Tarefa Humanitária que atua na gestão da crise migratória em Roraima ponderou que a interiorização dos imigrantes seria a solução mais adequada para lidar com o descontrolado incremento demográfico causado nesse estado, decorrente da entrada diária de centenas de pessoas vindas da Venezuela. Em abril do mesmo ano, iniciavam as ações de interiorização, por via aérea e terrestre, com esforços conjugados entre a Casa Civil da Presidência da República e o Alto Comissariado das Nações Unidas para os Refugiados (ACNUR). ${ }^{1}$ Desde 2019, essas ações ocupam um lugar central nos trabalhos executados pela Força Tarefa.

"Interiorização" é como se passou a denominar a medida político-administrativa pela qual o ente público (com ou sem parceria com entidades privadas e intergovernamentais) assume o ônus de transportar para outras partes do território nacional os migrantes estrangeiros que estejam concentrados demograficamente em algum estado ou município, de modo a distribuir o contingente populacional e, com isso, minorar o impacto sofrido localmente em relação à capacidade de oferta de postos de trabalho e de serviços públicos básicos.

Não é a primeira vez que o Brasil assume uma tal medida para lidar com uma crise migratória. No ápice da imigração haitiana no Brasil, em 2014, o governo do estado do Acre também decidiu implementar ações de interiorização como forma de reduzir a concentração demográfica dos imigrantes que ingressavam no país pela fronteira peruana. Em abril de 2013, o governo do Acre decretou estado de emergência no município de Brasileia (o mais afetado pela migração transfronteiriça). Meses depois (agosto), o Ministério da Saúde fez publicar uma portaria destinando R \$ 56 mil para compensar a sobrecarga no atendimento de saúde em função do grande fluxo migratório no município. ${ }^{2}$

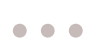

1 De acordo com dados da Casa Civil, atualizados até 5 de abril de 2019, 5.126 imigrantes venezuelanos já teriam sido interiorizados para outros estados brasileiros.

2 Cf. Portaria n. 1.833, de 27 de agosto de 2013, que "Define incentivo financeiro do Piso de Atenção Básica (PAB) fixo, para fins de compensação, ante ao fluxo migratório de haitianos no Município de Brasileia (AC)”. 
Embora com colaboração ocasional da iniciativa privada, por meio de empresas interessadas em contratar os trabalhadores migrantes, parte significativa dos custos do transporte rodoviário dos haitianos, desde os municípios fronteiriços de Assis Brasil, Epitaciolândia e Brasileia, até a capital Rio Branco, e de lá, por via terrestre ou aérea, para estados como Rondônia, São Paulo, Paraná, Santa Catarina, Mato Grosso e Rio Grande do Sul, foi assumida pelo ente estatal (UEBEL e RÜCKERT, 2017). A partir de março de 2015, com o aumento do endividamento em razão do fretamento de ônibus, o governo acreano passou a reclamar ajuda à União, sob a alegação de que a assistência aos migrantes seria matéria de competência federal (MAMED, 2016).

No recente caso venezuelano, em que o governo federal assumiu a gestão migratória em parceria com a Organização das Nações Unidas (ONU) e suas agências, a interiorização como estratégia voltou a ser defendida, inclusive pela própria ONU. Na página eletrônica da entidade, em maio de 2018, por ocasião da interiorização por via aérea de 29 venezuelanos para Cuiabá (MT), registrava-se que "O processo de interiorização de solicitantes de refúgio e migrantes vindos da Venezuela é uma das linhas de ações da Força Tarefa Humanitária em Roraima, apoiada pelo Sistema ONU no Brasil” (AGÊNCIA DA ONU PARA REFUGIADOS, 2018).

O quadro que torna indispensável a implementação da interiorização como ação estratégica continua sendo de dificuldades de inserção dos migrantes na sociedade local, incluindo limitações de ingresso no mercado de trabalho - cenário esse especialmente agravado no caso de Roraima, em que a economia é centrada em movimentações financeiras derivadas de empregos públicos (AUGUSTO e ISIDORO DE MORAIS, 2018). Como bem recordam Gustavo do Vale Rocha e Natália Vilar Pinto Ribeiro (2019, p. 557): “O objetivo dessa estratégia é diminuir a pressão sobre os serviços públicos do estado de Roraima, e, ao mesmo tempo, oferecer maior oportunidade de inserção socioeconômica aos imigrantes venezuelanos".

A intervenção estatal promovendo ou facilitando a interiorização buscaria atenuar os impactos sociodemográficos, como também econômicos e político-institucionais, que decorrem de fenômenos migratórios intensos e descontrolados. Investindo na interiorização, o Estado evita gastos que provavelmente teria de assumir em outros âmbitos com políticas públicas de seguridade social. A despeito de ser uma medida inteligente do ponto de vista gerencial e orçamentário, não é simples de ser executada - ou mesmo fundamentada.

Na migração venezuelana, há problemas de logística especialmente difíceis, pois Roraima é uma porta de entrada, mas não uma ponte para o território brasileiro. O estado se encontra em posição geográfica isolada da maior parte do país. Ele conta com acesso por via terrestre apenas com parte do estado do Amazonas - incluindo a capital Manaus - pela rodovia BR-174. Não há portos aquaviários nas cidades roraimenses mais sobrecarregadas pela migração, isto é, a cidade fronteiriça de Pacaraima e a capital Boa Vista. A alternativa mais viável é a mais custosa: o transporte aéreo. 
Para além disso, nem todos têm interesse na interiorização, que, a princípio, impediria a manutenção de contatos regulares, por meio da migração pendular, com o país natal (CAMARGO e HERMANY, 2018). Há os migrantes que mudam de lugar no país de destino, em função de oferta/possibilidade de trabalho ou de políticas governamentais de interiorização, mas há também os que ficam pela linha fronteiriça sem dela se afastar, como lembra Marilda C. Cavalcanti (2019).

Em março de 2018, a Subchefia Adjunta de Políticas Sociais (da Subchefia de Articulação e Monitoramento da Casa Civil) afirmava, aludindo à pesquisa feita pelo Ministério do Trabalho, que mais de 70\% dos imigrantes manifestaram, em entrevista, que tinham interesse na interiorização. Entretanto, considerando que pouco mais de 5 mil indivíduos o foram, ao longo de quase um ano após o início das interiorizações (PRESIDÊNCIA DA REPÚBLICA, 2019), tal quantitativo seria proporcionalmente pouco, considerando os dados da Polícia Federal, divulgados em outubro de 2018, que indicavam que, dos 176.259 venezuelanos que entraram por Pacaraima entre 2017 e 2018, não constava a saída do estado (por via aérea e terrestre) de 85.268 deles.

De vez que a interiorização é executada por meio de atos administrativos, o presente artigo discute alguns aspectos da motivação administrativa e da base legal desses atos. O método aqui empregado toma em consideração o conjunto de leis aplicáveis (e dos princípios subjacentes) à interiorização, e o interpreta tanto sistematicamente, buscando suplantar inconsistências e incoerências, quanto literalmente, dando contornos rigorosos às definições utilizadas nos atos normativos. O objetivo é verificar o alcance que eles podem ter em uma interpretação sistemática mais generosa e em uma interpretação literal mais cuidadosa.

Primeiro, seria importante que se elucidasse se, sendo uma medida voltada ao desinchaço de regiões marcadas pelo excesso demográfico, ela poderia beneficiar não apenas estrangeiros, mas também nacionais que se encontrem nessas regiões e que, sendo interiorizados, também contribuiriam para acelerar o desinchaço. É necessário indagar, nesse passo, se os nacionais deveriam ter reconhecido para si um direito à interiorização equiparável ou extensível àquele prestado aos migrantes (no presente caso, os venezuelanos). ${ }^{3}$

A rigor, deveria ser esclarecido, inclusive, se a interiorização poderia ser demandada em outros contextos de incremento demográfico descontrolado que não a migração internacional, por exemplo, o de cidades afetadas gravemente pelo êxodo rural ou pela migração

3 Apesar de a história nacional registrar casos de migrações orientadas por políticas governamentais de atração de mão de obra, em que a Administração de determinado ente assume, como investimento, a responsabilidade pela cooptação de trabalhadores vindos de outros estados ou países, veja-se que a interiorização envolve uma responsabilidade distintivamente mais ampliada, cuja realização hoje depende de um conjunto de disposições administrativas. 
interna. A própria discussão sobre se a medida constituiria um dever ou uma simples liberalidade do Estado deveria vir à tona. É mesmo curioso que essas questões ainda não tenham sido examinadas e exauridas em fóruns acadêmicos e administrativo-burocráticos.

\section{A INTERIORIZAÇÃO COMO EXPERIMENTO POLÍTICO-ADMINISTRATIVO}

Experiências em países que atraem e recebem migrantes revelam que, por diversos fatores, a concentração geográfica de determinados contingentes em certas regiões do país é uma tendência recorrente, e convém aos governos fazer algo em relação a isso, implementando medidas de distribuição e redistribuição da população migrante (NEWBOLD, 1999; HOU, 2005). No caso de Roraima, tais fatores seriam, principalmente, o isolamento geográfico do território do estado e a fronteira terrestre favorável a deslocamentos pendulares ocasionais.

Como o estado tem baixa densidade demográfica, em termos comparativos, ${ }^{4} \mathrm{e}$ as ofertas de trabalho estão concentradas em vagas no serviço público, a imigração intensa de venezuelanos, a partir de 2016, deixou expostos os limites de capacidade do governo local (inclusive os governos municipais) e da iniciativa privada.

Durante a $2^{a}$ reunião do Comitê Federal para a Assistência Emergencial (vinculado à Casa Civil da Presidência da República), em março de 2018, a interiorização dos imigrantes foi apresentada como uma estratégia a ser "desenvolvida por vários ministérios com o apoio de agências internacionais vinculadas à Organização das Nações Unidas”. ${ }^{5}$ Na ocasião, a Subchefia de Articulação e Monitoramento da Casa Civil afirmava que a interiorização era uma ação inédita (PRESIDÊNCIA DA REPÚBLICA, 2018a), desconsiderando a experiência anterior da Administração Pública federal no caso da migração haitiana. O ineditismo, no entanto, poderia ser considerado verdadeiro, ao se perceber que o grau de institucionalidade que a interiorização passou a ter com a migração venezuelana é, de fato, algo inaudito.

Nessa reunião, foram planejadas etapas para a implementação gradual da interiorização, do modo seguinte: $1^{a}$ etapa: levantamento e priorização das cidades dispostas a recebê-los, com a avaliação de vagas para o abrigamento deles em instalações públicas e privadas; $2^{a}$ etapa: continuidade do cadastro dos imigrantes, incluindo entrevista com os interessados na

$4 \quad$ O estado contava com 505.665 habitantes, segundo o Censo de 2015 do Instituto Brasileiro de Geografia e Estatística (IBGE).

5 Cf. a Ata da Reunião do Comitê Federal de Assistência Emergencial para Acolhimento a Pessoas em Situação de Vulnerabilidade decorrente de Fluxo Migratório provocado por Crise Humanitária, em especial o seu item 3, linhas 65 a 68. Disponível em: http://www.casacivil.gov.br/operacao-acolhida/documentos/ ata-2a-reuniao-comite-federal-de-assistencia-emergencial. Acesso em: 19 maio 2019. 
interiorização, com o auxílio do ACNUR; $3^{a}$ etapa: articulação operacional entre os estados da federação interessados; e $4^{a}$ etapa: seleção dos imigrantes a serem interiorizados, com a participação da Organização Internacional para as Migrações - OIM (PRESIDÊNCIA DA REPÚBLICA, 2018a).

O destinatário das ações, que teria prioridade na seleção, havia sido definido ali claramente: as pessoas abrigadas em Boa Vista, regularizadas no Brasil, com carteira de trabalho, vacinadas (imunizadas) e, por evidente, interessadas em participar da ação.

Àquela época, março de 2018, o contingente de imigrantes nos abrigos era de cerca de 1.300 pessoas (PRESIDÊNCIA DA REPÚBLICA, 2018a), e, como a própria Subchefia de Articulação e Monitoramento da Casa Civil reconhecia que nem todos os abrigados teriam interesse na interiorização, chama a atenção como o Comitê Federal pretendia que uma tal medida pudesse obter qualquer impacto significativo na diminuição da pressão que as demandas dos migrantes exerciam à época.

Não se podia ignorar, conforme pesquisas realizadas entre 2017 e 2018 , que menos de $8 \%$ dos migrantes venezuelanos em Boa Vista se encontrava abrigada, e, considerando a população migrante geral (abrigada e não abrigada), cerca de metade dos venezuelanos estava empregada. Desta, cerca de 50\% recebia menos de um salário mínimo por mês, e quase 45\% recebia entre um e dois salários mínimos (SIMÕES, CAVALCANTI e OLIVEIRA, 2018). ${ }^{6}$

Em matéria para a Folha de S.Paulo de abril de 2019, informando que a interiorização de pouco mais de 5 mil venezuelanos havia “aliviado” o estado de Roraima, a jornalista Flávia Mantovani (2019) reconhecia que havia ainda cerca de 1.600 pessoas migrantes em situação de rua, segundo dados do Exército Brasileiro e da OIM de março de 2018. Daniela Arguilar Camargo e Ricardo Hermany, em agosto de 2018, diziam que a interiorização ainda se mostrava "simbólica ante ao número de ingressos", defendendo que a União deveria envidar esforços para que a medida pudesse seguir "no mesmo ritmo da proporção da entrada [de migrantes]" (2018, p. 247).

Em todo caso, afastando críticas injustas quanto ao seu mérito, reconheça-se que, no caso brasileiro, a interiorização foi planejada como um experimento, que declaradamente não se apresentava como "solução única e definitiva" capaz de "abarcar toda a população imigrante”, e a sua oferta à população-alvo deveria ser feita de forma “cuidadosa”, uma vez que os agentes envolvidos não poderiam antever "o real cenário que [os migrantes] vão encontrar no seu destino” (PRESIDÊNCIA DA REPÚBLICA, 2018a, p. 2). Conforme se disse, como a interiorização passou a figurar com destaque em um projeto inovador, interinstitucional,

6 Cf., em especial, as tabelas 16,19 e 21 do artigo. 
de larga abrangência, pouco se poderia saber acerca dos objetivos, do alcance e dos procedimentos dessa medida ainda em abril de 2018 (SAMPAIO e SILVA, 2018).

Para acompanhar os trabalhos que iniciariam, foi criado o "Subcomitê Federal para Interiorização dos Imigrantes que se encontram no Estado de Roraima”, instituído pela Resolução n. 02, de 26 de março de 2018 (do Comitê Federal para Assistência Emergencial). ${ }^{7}$ $\mathrm{O}$ art. $4^{\circ}$ dessa resolução dispunha que o Subcomitê deveria apresentar, a cada mês, relatório de suas atividades ao Comitê Federal. No entanto, o que adquiriu notoriedade foram os primeiros relatórios trimestrais do próprio Comitê: o primeiro, de maio, e o segundo, já de outubro de 2018. Ambos sintetizavam, em capítulos próprios sobre a interiorização, os trabalhos levados a cabo pelo Subcomitê, sob coordenação do Ministério do Desenvolvimento Social.

No Relatório Trimestral de maio, é relevante a definição fixada para a interiorização, como: "A estratégia [...] que desloca imigrantes para outros estados brasileiros com apoio do Governo Federal, tem como objetivo oferecer maiores oportunidades de inserção socioeconômica aos imigrantes venezuelanos e diminuir a pressão sobre os serviços públicos do estado de Roraima" (PRESIDÊNCIA DA REPÚBLICA, 2018b, p. 13, grifo nosso). Para os propósitos deste artigo, essa definição é tomada em consideração para analisar a motivação latente nos atos implementados pelo poder público, voltados a materializar as etapas de consecução da estratégia de interiorização.

\section{A INTERIORIZAÇÃO COMO DIREITO LEGAL}

Ainda em fevereiro de 2018, o governo federal propôs à Mesa Diretora do Congresso Nacional a Medida Provisória n. 820, que trazia em seu art. $4^{\circ}$, X, o seguinte:

Art. $4^{\circ}$ As medidas de assistência emergencial para acolhimento a pessoas em situação de vulnerabilidade decorrente de fluxo migratório provocado por crise humanitária visam à ampliação das políticas de:

$[\ldots]$

$\mathrm{X}$ - mobilidade, distribuição no território nacional e apoio à interiorização das pessoas mencionadas no caput. (grifo nosso)

Esse dispositivo apresentava o apoio à interiorização como uma política relacionada à mobilidade, e dependente esta das medidas de assistência emergencial a serem empreendidas em

7 Publicada no Diário Oficial da União de 29.03.2018, n. 61, Seção 1, p. 1. 
favor das pessoas "em situação de vulnerabilidade decorrente de fluxo migratório provocado por crise humanitária".

Essa norma do inciso X parece conectar-se, pelo menos em sua primeira parte ("mobilidade"), com a do inciso II do art. $4^{\circ}$ da Lei de Migração (Lei n. 13.445/2017), que prevê o direito à liberdade de circulação em território nacional como garantia a ser assegurada aos migrantes. Essa outra norma disporia sobre um direito subjetivo cuja realização demandaria do Estado uma prestação negativa, a saber, de não obstar a liberdade de locomoção do imigrante que pretendesse circular no território nacional, tal como não é dado fazê-lo aos nacionais. Nesse caso, bastaria que o poder público não empreendesse ações de cerceamento da liberdade de ir e vir para que o direito fosse respeitado. A contrario sensu, não se desconsidera que o livre movimento resta também minado, em alguma medida, quando o Estado não fornece aos grupos vulneráveis meios materiais de realizá-lo, mas, em todo caso, isso não significa dizer que o direito à mobilidade ou à livre circulação seriam necessariamente prestacionais. ${ }^{8}$

De modo diverso, a última parte do inciso X ("apoio à interiorização"), que dispõe sobre um direito de prestação positiva, a demandar do Estado apoio para viabilizar o exercício amplo da livre circulação aos migrantes desfavorecidos, não parece encontrar na Lei de Migração, de forma inconfundível, um dispositivo de reforço. É verdade que o inciso VIII do art. $4^{\circ}$ estabelece que ao migrante também será assegurado o acesso aos serviços públicos de assistência social, porém não é certo que os deveres assistenciais do Estado incluem o de apoiar a interiorização de pessoas pelo território nacional, mesmo porque não está definitivamente estabelecido que os vulneráveis nacionais teriam um tal direito, ${ }^{9}$ o qual pudesse ser estendido, por isonomia, aos migrantes em situação de vulnerabilidade. Frise-se que o caput do art. $4^{\circ}$, que alberga os incisos II (liberdade de circulação) e VIII (assistência social), fala de garantias aos migrantes "em condição de igualdade com os nacionais".

A propósito, o art. $3^{\circ}$ da Medida Provisória n. 820, em sua redação original, dispunha que

8 Recorde-se a origem histórica do direito à liberdade de locomoção, intrinsecamente ligado ao habeas corpus e significando, tão somente, o direito individual de não ser constrangido no exercício legítimo de ir e vir.

9 Não se entende que situações previstas em lei, por exemplo, a gratuidade em transporte rodoviário interestadual a idosos, pessoas com deficiência e jovens de baixa renda, embora sejam políticas assistenciais destinadas a grupos vulneráveis, poderiam ser análogas à política de interiorização, uma vez que constituem, aquelas, reserva de vagas admitidas por empresas privadas concessionárias do serviço e que dependem de disponibilidade de assentos, o que é distinto de uma política assistencial para o transporte interestadual exclusivo para grupos vulneráveis. 
[a]s medidas de assistência emergencial para acolhimento a pessoas em situação de vulnerabilidade decorrente de fluxo migratório provocado por crise humanitária têm o objetivo de articular ações integradas destinadas a pessoas, nacionais ou estrangeiras, que façam parte de fluxo migratório [...]. (grifo nosso)

Conforme se vê, concebia-se, inicialmente, que as pessoas vulnerabilizadas em razão da crise humanitária decorrente do fluxo migratório seriam não somente os imigrantes, mas também, em alguns casos, os nacionais.

A citada medida provisória foi convertida na Lei n. 13.684, de 21 de junho de 2018, quando então foram suprimidas as expressões mencionadas, conforme se pode ler de seu art. $4^{\circ}$ :

Art. $4^{\circ}$ As medidas de assistência emergencial para acolhimento a pessoas em situação de vulnerabilidade decorrente de fluxo migratório provocado por crise humanitária têm o objetivo de articular ações integradas a serem desempenhadas pelos governos federal, estaduais, distrital e municipais, por meio de adesão a instrumento de cooperação federativa, no qual serão estabelecidas as responsabilidades dos entes federativos envolvidos.

No decorrer da apreciação congressual, muitos deputados e senadores propuseram emendas solicitando a substituição da expressão "estrangeiros" por "migrantes", mas não houve nenhum deles que se manifestasse, ao menos oficialmente, contra a presença do termo "nacionais".

O próprio inciso $X$, em sua versão final, restou ampliado para contemplar outros mecanismos de realocação de migrantes, os quais, em todo caso, não se confundem com a interiorização, a saber: "[...] mobilidade, contemplados a distribuição e a interiorização no território nacional, o repatriamento e o reassentamento das pessoas mencionadas no caput deste artigo".

As políticas de mobilidade a serem ampliadas pela assistência aos migrantes, em consonância com os princípios de livre movimento (SAMPAIO e SILVA, 2018), seriam, portanto, nos termos da lei, de quatro tipos ou espécies: (i) de distribuição, de âmbito intraestadual; (ii) de interiorização em território nacional (interestadual); (iii) de repatriamento ou repatriação, como medida administrativa de devolução de pessoa em situação de impedimento ao país de procedência ou de nacionalidade (cf. o art. 49 da Lei de Migração); e (iv) de reassentamento, como medida administrativa de realocação (cf. os arts. 35 e seguintes do Decreto $\mathrm{n}$. 9.985/2000), que parece visar aos povos indígenas e às comunidades tradicionais referidas no inciso VI do art. $5^{\circ}$ da Lei n. 13.684/2018.

O mais marcante da conversão da medida provisória talvez tenha sido o veto a um parágrafo $\left(\S 5^{\circ}\right)$ que foi acrescentado ao art. $5^{\circ}$, e que, a propósito, tratava da instituição de cotas de imigrantes a serem absorvidas pelos estados receptores, as quais deveriam ser 
observadas nas medidas de distribuição e interiorização. As razões do veto, conforme a Mensagem Presidencial n. 347, de 21 de junho de 2018, teriam sido levantadas pelo então Ministério de Direitos Humanos, e se voltavam propriamente contra a ideia de "cotas", uma vez que elas seriam, no entender do Poder Executivo, contrárias ao direito constitucional de livre locomoção. O veto não foi derrubado pelo Legislativo.

Em pleno vigor a Lei n. 13.684/2018, um primeiro questionamento que surge é se ela teria estabelecido direitos subjetivos de mobilidade, entre os quais o direito à interiorização em território nacional, bem como, em caso positivo, qual seria então a natureza desse direito.

De modo objetivo, é correto dizer que sim, que essa legislação estabelece “a pessoas em situação de vulnerabilidade decorrente de fluxo migratório provocado por crise humanitária” o direito de serem, às expensas do ente público (a Administração direta, envolvendo obrigatoriamente o ente federal, e eventualmente cooperando com organismos internacionais ${ }^{\mathbf{1 0}}$ e com a sociedade civil), mobilizadas (transportadas) para outros estados da federação em que haja melhores condições sociais de acesso a emprego, renda e seguridade social.

Portanto, a interiorização seria um direito que se poderia reconhecer, de modo incontroverso, em favor de pessoas migrantes socialmente vulnerabilizadas em virtude de uma crise humanitária. Ao fixá-lo, a Lei n. 13.684/2018 teria inovado, porquanto nem na Lei de Migração (que prevê os direitos de migrantes), nem na Lei Orgânica da Assistência Social ${ }^{11}$ - LOAS (que prevê os direitos de necessitados) -, nem mesmo na Constituição Federal ${ }^{12}$ (que prevê direitos fundamentais de cidadania), há dispositivo que já o tivesse reconhecido expressamente. Isso não significa, porém, que não haja princípios e diretrizes nessas e em outras normas capazes de respaldar juridicamente o direito à interiorização de migrantes vulneráveis (de baixa renda ou sem renda), tampouco significa, porque seria absurdo supô-lo, que esse direito precisaria já estar previsto anteriormente para ser então reafirmado na lex novae. Nada impedia que a Lei n. 13.684/2018 criasse esse direito social, como eficazmente

10 No caso da migração venezuelana, os organismos internacionais que têm cooperado diretamente com o governo são a ONU, através do ACNUR, do Fundo de População das Nações Unidas (UNFPA) e do Programa das Nações Unidas para o Desenvolvimento (Pnud), e a OIM.

11 O art. 2 ${ }^{\circ}$, I, “c”, da LOAS (Lei n. 8.742/93) dispõe que a assistência social tem por objetivo a "promoção da integração ao mercado de trabalho", mas disso não se pode deduzir, de modo direto e imediato, o direito à interiorização. E, mesmo se se pudesse, esse direito seria dependente do princípio da universalidade dos direitos sociais, previsto na LOAS (parágrafo único do art. $2^{\circ}$ e inciso II do art. $4^{\circ}$ ), de modo a ter como destinatários quaisquer famílias ou indivíduos em situações de vulnerabilidade ou risco social, independentemente da nacionalidade.

12 Embora o art. $6^{\circ}$, caput, da Constituição preveja o transporte como um direito social, o inciso IV do art. $7^{\circ}$, logo em seguida, vincula-o ao salário mínimo, como um direito dos trabalhadores urbanos e rurais; ou seja, está tratando do direito que tem o trabalhador de dispor de um mínimo para deslocar-se ao trabalho. 
o fez; e, a propósito, o fez amparada tanto em motivação imanente quanto em princípios gerais do direito, como a cidadania e a dignidade da pessoa humana.

Entretanto, um segundo questionamento, que advém justamente do reconhecimento do novo direito social firmado, é se, a partir daquelas normas e princípios gerais, esse direito não poderia ser reinterpretado e estendido em favor também de nacionais, desde que também estes fossem comprovadamente vulneráveis, alijados do mercado de trabalho e aprisionados a um contexto social incapaz de promover a sua dignidade. Mais ainda: um nacional vitimado pela falta de oportunidades em um contexto de flagelo social relacionado a um fluxo migratório desordenado, causado não por crise humanitária estrangeira, mas sim por deslocamento forçado interno, ou por êxodo rural, teria também direito à interiorização?

Os propósitos deste artigo não devem ser lidos de maneira enviesada, porque o que se está fazendo aqui não é sugerir que há tratamento discriminatório por parte do Estado que favoreça imigrantes em detrimento de nacionais, mas, diversamente, se está questionando se há qualquer razão jurídica para negar que um direito social recém-estabelecido - com justeza - e a política pública que o implementa sejam tratados como universalizáveis. Não deveria o Estado interiorizar igualmente os nacionais que estejam em situação equiparável aos estrangeiros que têm direito à interiorização?

\section{AS POLÍTICAS E AS NORMAS DE INTERIORIZAÇÃO: MIGRATÓRIAS OU SOCIAIS?}

Uma parte considerável das dúvidas sobre a possibilidade de universalização da interiorização, de maneira que passe a atender nacionais, estaria ligada à incerteza da tônica que possui essa política de mobilidade regulada por lei. Seria ela, essencialmente, uma política migratória ou social?

É compreensível que exista a tentação de afirmar que ela é as duas coisas conjugadamente - e o é mesmo -, porém isso não significa que ela seja ambas (migratória e social) em igual medida. Saber qual a ênfase que a impulsiona tem implicações de ordem prática.

Se se tratar de uma política mais migratória, então é possível dizer que ela deve atender migrantes em geral, mas podendo estabelecer critérios que restrinjam as benesses nela contidas aos migrantes desassistidos. Contudo, para ser uma política migratória, ela deveria estar relacionada a ações governamentais próprias ao tema da migração, em especial à fixação de critérios para o controle de entrada e permanência de estrangeiros no território nacional (HAAS e NATTER, 2015), capazes de afetar (restringindo ou reforçando) fluxos migratórios.

Ainda que não seja impossível imaginar a subvenção pelo poder público do transporte, inclusive interestadual, de pessoas necessitadas, que não aufiram renda, isso é diverso de uma política pública que promova periodicamente o transporte exclusivo dessas pessoas pelo território nacional (ver nota 9). 
Por evidente, alguém poderia alegar que as políticas migratórias têm um espectro mais largo que o controle de fronteiras. As definições mais correntes de política migratória no plano internacional, contudo, tendem a delimitá-la no sentido de que seja considerada "[um conjunto de] regras (i.e., leis, regulamentos e medidas) que os Estados nacionais definem e implementam com o objetivo (muitas vezes apenas implícito) de afetar o volume, a origem, a direção e a composição interna dos fluxos migratórios” (CZAIKA e HAAS, 2013, p. 489), ou "[um conjunto de] medidas informais e formais projetadas para reger a entrada, permanência e retorno de migrantes" (HANSEN, 2007, p. 330). Qualquer que seja a política migratória, conforme Maria Ioannis Baganha (2005, p. 30), ela "tem que começar por resolver duas questões de natureza totalmente diversa, uma vez que uma é de ordem quantitativa, isto é, quantos imigrantes deve o país receber, e a outra é de carácter qualitativo, ou seja, qual deve ser o perfil dessas pessoas".

No Brasil, em razão de o controle das fronteiras estar a cargo da Administração federal, e de a competência legislativa para temas de emigração e imigração recair sobre a União (art. 22, XV, da Constituição), a impressão é de que a política migratória seria exclusivamente federal. Entretanto, como o impacto migratório alcança multidimensionalmente (e indistintamente) os demais entes federativos (estados e municípios), não é incorreto supor que uma política migratória comprometida com a própria efetividade deveria levar em conta políticas públicas coordenadas e verticalmente integradas entre os entes (XAVIER, 2012). Embora governos estaduais e municipais - mesmo aqueles com fronteiras internacionais não tenham competências relativas ao controle de entrada e permanência de imigrantes, podem colaborar com órgãos federais para o desempenho de atividades policiais ou assistenciais das quais dependem as políticas migratórias e de fronteiras.

Um esclarecimento das competências específicas ou compartilhadas dos entes e órgãos públicos deveria ser feito com a regulamentação do art. 120 da Lei de Migração, que prevê uma "Política Nacional de Migrações, Refúgio e Apatridia”. A finalidade dessa política seria, oportunamente, "coordenar e articular ações setoriais implementadas pelo Poder Executivo federal em regime de cooperação com os Estados, o Distrito Federal e os Municípios”. Até o presente momento, todavia, não foi editado nenhum ato normativo pelo Executivo federal ${ }^{13}$ (conforme o $\S 1^{\circ}$ do art. 120) que definisse os objetivos, a organização e a estratégia para a coordenação de uma tal política nacional, o que contribui para a dilatação das dificuldades de implementação da gestão migratória.

O que há, por ora, são diversos princípios e diretrizes que, listados na Lei de Migração $\left(\right.$ art. $3^{\circ}$ ), orientam a difusa política migratória brasileira. Entre eles, convém destacar, para problematizá-lo, o primeiro princípio da lista, a saber, o da "universalidade, indivisibilidade e

13 Camila B. Breitenvieser (2019, p. 20) recorda que "O Decreto 9.199/2017, que regulamenta a Lei 13.445/ 2017, não versou sobre a implementação do artigo 120”. 
interdependência dos direitos humanos" (inciso I). Permitindo entrever o intento do legislador de revestir o tema migratório de uma abordagem humanista, esse princípio, todavia, não deixa claro o seu escopo.

O princípio da "universalidade, indivisibilidade e interdependência dos direitos humanos" aplicado à política migratória possivelmente quer recordar que, quanto mais direitos fundamentais forem reconhecidos em favor de populações migrantes, tanto melhor, tendo em conta que esses direitos, de diferentes dimensões, complementar-se-iam em alguma medida quando reunidos.

Assim, a política migratória não seria universal em si mesma, isto é, não se poderia concebê-la como incompatível com qualquer tipo de limitação quanto aos seus beneficiários, mesmo porque se pode notar que certas políticas migratórias têm destinatários específicos, por exemplo, aquela do Conselho Nacional de Imigração (CNIg) que dispôs sobre a concessão de visto humanitário para os imigrantes haitianos (Resolução Normativa n. 97/2012).

O princípio da universalidade se revelaria mais promissor no caso dos direitos humanos sociais, ou propriamente nas políticas sociais. Embora estas também possam selecionar o seu alvo em relação aos beneficiários, considera-se que as políticas sociais, quando universais, são mais eficazes do que as seletivas na promoção da igualdade e da confiança social (ROTHSTEIN e USLANER, 2005). Bem por isso, a LOAS (art. $2^{\circ}$, parágrafo único, e art. $4^{\circ}$, II) faz referência expressa à universalização dos direitos sociais, no sentido de que se deve prover dos "mínimos sociais" toda e qualquer pessoa com necessidades básicas - ainda que venha a priorizar certos grupos (v.g., crianças e adolescentes carentes, pessoas com deficiência, mães, etc.).

Elas podem ser focais na implementação, mas não na natureza; quer dizer, elas são devidas aos desfavorecidos em geral, ainda que, na prática, alcancem apenas alguns entre eles. É possível imaginar, por exemplo, um plano ou projeto que se concentre na prestação de medidas em favor de moradores de rua ou de pessoas pobres que dependem de transporte público, mas isso não significa que eles (plano ou projeto) têm o condão de reservar para esses grupos (moradores de rua, beneficiários do sistema de transporte público ou outros) a titularidade exclusiva do direito de receber provisões ou compensações do Estado.

De todo modo, sobre a natureza da política da interiorização, resta então saber se se trata, em última instância, de uma política que tem a ver com a regulação de fluxos migratórios ou com o enfrentamento de processos de marginalização social. A importância dessa diferenciação reside justamente no fato de que, em contextos de recepção de contingentes migratórios, tensões entre o sistema de controle migratório e as redes de proteção social (formais e informais) costumam impactar diretamente nas possibilidades concretas de promoção, pelos governos, de bem-estar às comunidades migrantes. Citando o exemplo francês, Maybritt Jill Alpes (2015, p. 303) assinala que "as contradições entre a política de migração e a política social resultaram em situações perversas, com efeitos adversos nas condições de vida das famílias migrantes e nos gastos públicos”. 
Que as políticas migratória e social estão relacionadas entre si, pode-se depreender do fato mesmo de que a execução da política de interiorização compreende um arranjo de esforços interministeriais, contando o Subcomitê de Interiorização com o apoio do Ministério da Justiça e Segurança Pública, Ministério do Desenvolvimento Social, Ministério do Trabalho e Emprego e Ministério da Saúde. Contudo, embora programaticamente convergentes, essas políticas frequentemente opõem funcionários e agentes, e por vezes tendem a demarcar os limites de atuação de órgãos e instituições.

Dessa maneira, devendo-se distingui-las para relacionar a medida de interiorização mais propriamente a uma ou outra, recorre-se uma vez mais à definição legal contida no Relatório Trimestral do mês de maio, do Subcomitê Federal. Nessa definição, vê-se que a medida, embora focando os venezuelanos, estaria comprometida com o oferecimento de maiores oportunidades de inserção socioeconômica aos necessitados, deslocando a mão de obra migrante para outros estados de modo a diminuir a sobrecarga sobre Roraima. Tem a interiorização, por isso, expresso objetivo de “ajudar os venezuelanos em vulnerabilidade a encontrar melhores condições de vida em outros Estados, sem sobrecarregar nenhuma região" (TÜZÜN, 2018, p. 1703-1704).

É incontestável que essa abordagem da interiorização está mais próxima àquela das políticas sociais e, como tal, tem um potencial de universalização que permite uma interpretação extensiva em favor dos migrantes em geral (e não apenas venezuelanos) e também dos nacionais, desde que socialmente carentes.

Nos termos do Segundo Relatório Trimestral do Comitê Federal, que ampliou as modalidades de interiorização, de modo a compreender não apenas a interiorização com abrigamento, mas também a interiorização para reunificação familiar (a partir de setembro de 2018) e a interiorização por sinalização de vaga de trabalho, o aspecto de proteção social se mantém presente.

À vista disso, pode-se determinar que a interiorização seria um direito subjetivo de mobilidade, com natureza (ou caráter) social, destinado a atender uma categoria considerada socialmente vulnerável. O exercício desse direito estaria, por certo, dependente da manifestação livre do consentimento informado dos seus titulares.

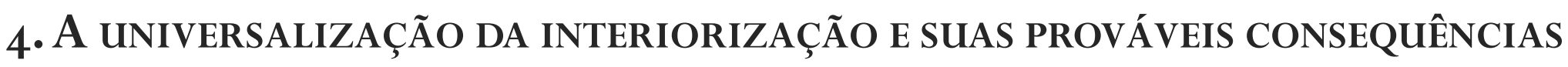 JURÍDICO-POLÍTICAS}

Defender a universalização do direito à interiorização, como aqui se faz, significa postular a sua concessão a todos os sujeitos que se encontrem em situação de vulnerabilidade social causada por um incremento demográfico crítico e, consequentemente, pelo exaurimento do sistema de seguridade social e pela diminuição drástica de ofertas de trabalho em âmbito local. Essa defesa implica, conforme se afirma, ampliar o conjunto dos beneficiários da medida de interiorização, de maneira a incluir migrantes de quaisquer nacionalidades (inclusive 
migrantes internos) ou outros grupos nacionais afetados por uma situação de crise humanitária e social. Assim pensada, a interiorização seguiria consonante com as motivações subjacentes ao policy-making que a gerou, e teria agora, inclusive, o condão de afastar reações xenofóbicas que a acusam de seletividade injustificada em desfavor dos nacionais.

Sem dúvidas, essa ampliação que se defende ocasionaria objeções de ponto de vista do orçamento e das finanças públicas. Quem poderia custear tantas demandas por interiorização que se tornariam juridicamente possíveis?

Esse questionamento seria essencialmente o mesmo que objeta as possibilidades de promoção dos demais direitos sociais. E a resposta mais adequada a ele deveria levar em consideração uma cláusula própria dos direitos sociais, a saber, a da progressividade desses direitos (prevista em tratados de direitos humanos dos quais o Brasil é parte), segundo a qual o Estado deve se comprometer a satisfazê-los em marcha contínua, conforme as suas possibilidades materiais. O conhecido argumento da reserva do possível poderia vir a ser suscitado nesse caso, e caberia ao Poder Judiciário, na hipótese de judicialização, averiguar tanto o seu eventual cabimento em situações específicas quanto a sua jusfundamentalidade em termos abstratos.

É de se ressaltar também que o dever de interiorização de contingentes populacionais estaria configurado para o Estado apenas em situações excepcionais, em que determinada região do território fosse afetada por crise demográfica com comprometimento da prestação de serviços básicos. Seria, dessa forma, um direito social de prestação não ordinária, não frequente, à diferença de tantos outros que compõem a mesma categoria.

De vez que a interiorização fosse adotada como uma medida preventiva, para evitar os colapsos comuns do inchaço demográfico, não é possível precisar ex ante se, tornada acessível a todos, os estrangeiros seriam o contingente mais disposto a participar dela. Em verdade, seria até provável que não, se se considerar que há uma tendência natural dos imigrantes de se concentrarem geograficamente em certas regiões nos países de destino. Esse fenômeno foi muito apropriadamente percebido por Barry R. Chiswick, Yew Liang Lee e Paul W. Miller (2002, p. 3), quando analisaram os efeitos dos processos migratórios na Austrália:

Uma característica comum aos imigrantes em vários destinos e em vários períodos de tempo é que eles tendem a estar geograficamente concentrados, ou seja, tendem a viver em concentrações ou enclaves de imigrantes. Os imigrantes de uma origem específica tendem a viver em áreas onde vivem outros da mesma origem, em vez de se distribuírem pelas regiões de destino na mesma proporção que a população nativa. [...] De fato, elas [as concentrações] surgem mesmo quando as políticas públicas preferem dispersar os imigrantes pelo país anfitrião.

Verificando no Brasil essa tendência, o governo deveria apoiar ou prestar políticas de incentivo aos imigrantes, as quais enfocassem não tanto as oportunidades laborais em outras regiões, 
mas sim a relevância que há para a sedimentação da força política dos grupos imigrantes em nível nacional o fato de eles estarem distribuídos de modo mais homogêneo pelas várias regiões do país acolhedor (CHISWICK, LEE e MILLER, 2002).

Esses incentivos das políticas de interiorização não desconfigurariam o seu traço universalista. Seriam, antes, um apelo para que os imigrantes, ponderando ganhos de representatividade política a médio prazo, buscassem participar ativamente de caravanas de interiorização eventualmente montadas pelo Estado em circunstâncias excepcionais.

\section{CONCLUSÃO}

O atual plano de interiorização implementado no norte do Brasil, para aliviar o estado de Roraima, foi elaborado como uma medida político-administrativa voltada ao desinchaço populacional desse estado, o qual passou a experimentar, com a imigração venezuelana descontrolada a partir da segunda metade da década de 2010, uma extraordinária pressão no serviço público e no mercado de trabalho.

No contexto da crise migratória de venezuelanos em Roraima, foram editados atos normativos, entre os quais se destaca a Lei n. 13.684/2018 (resultado da conversão da Medida Provisória n. 820/2018), na qual a interiorização foi catalogada como uma política de mobilidade a ser implementada em situações emergenciais para prestar assistência a pessoas em situação de vulnerabilidade decorrente de processos migratórios críticos.

Em primeiro lugar, pode-se dizer que essa legislação formalizou, no Brasil, o direito subjetivo à interiorização. Esse direito de mobilidade, assim como a política a implementá-lo, teriam natureza mais social do que migratória, uma vez que estariam diretamente relacionados com a promoção de assistência e proteção (incluindo estratégias de inserção laboral) a pessoas em situação de vulnerabilidade social.

Embora a lei tenha como fonte material, claramente, a crise humanitária de Roraima, o seu texto, redigido em termos gerais, permite que um tal direito social, à vista do princípio da universalidade própria dos direitos sociais, seja interpretado extensivamente, para abarcar como beneficiários os necessitados e vulneráveis em geral, independentemente da nacionalidade que tenham. Essa interpretação extensiva não trairia, nem frustraria, os propósitos últimos da interiorização, isto é, de fazer diminuir a pressão sobre a rede de proteção social e aumentar as possibilidades de ofertas de trabalho no local atingido pelo aumento demográfico. Esses propósitos continuariam podendo ser alcançados com a interiorização quer de estrangeiros (imigrantes), quer de nacionais. Em ambos os casos, a interiorização produziria a distribuição demográfica equitativa do excedente populacional entre os demais estados da federação, aliviando o estado abalado.

Não há nada de errado, em termos legais, com a atual política de interiorização de venezuelanos. Como dito, ela apenas tem o condão de tornar possível que o direito à interiorização, uma vez reconhecido, seja vindicável por outros grupos e em outras situações, que 
não apenas por estrangeiros em casos de migração internacional. Restaria aos tribunais, para o futuro, as tarefas tanto de confirmação do direito social à interiorização em favor de nacionais, respeitado o requisito da existência de crise humanitária (provocada por deslocamentos massivos), quanto de delimitação de seu caráter de direito fundamental componente de um mínimo existencial.

Supondo que, aberta a todos, a possibilidade de interiorização passasse a ser mais requerida por nacionais do que por migrantes, seria então necessária alguma política de incentivo à interiorização dos imigrantes estrangeiros, ressaltando a eles as vantagens sociopolíticas de estarem representados proporcionalmente em várias regiões do país.

\section{REFERÊNCIAS}

AGÊNCIA DA ONU PARA REFUGIADOS. ONU Brasil apoia nova interiorização de cidadãos venezuelanos para Cuiabá. 15 maio 2018. Disponível em: https://www.acnur.org/portugues/2018/05/15/onubrasil-apoia-nova-interiorizacao-de-cidadaos-venezuelanos-para-cuiaba/. Acesso em: 19 jan. 2021.

ALPES, Maybritt Jill. Social protection and migration control: The case of migrant care workers and Parisian welfare hotels. Transnational Social Review, v. 5, n. 3, p. 296-311, 2015. doi: 10.1080/ 21931674.2015.1082781.

AUGUSTO, Isabel Regina; ISIDORO DE MORAIS, Vângela Maria. Brasil profundo: a identidade nacional a partir da recepção midiática da interiorização dos imigrantes venezuelanos. Revista del CESLA. International Latin American Studies Review, v. 22, p. 265-296, 2018.

BAGANHA, Maria Ioannis. Política de imigração: a regulação dos fluxos. Revista Crítica de Ciências Sociais [on-line], n. 73, p. 29-44, 2005. Disponível em: http://journals.openedition.org/rccs/952. Acesso em: 23 maio 2019.

BREITENVIESER, Camila Barrero. Políticas para migrantes: formação da agenda do Governo Municipal de São Paulo. 2019. 205 f. Dissertação (Mestrado CMAPG) - Escola de Administração de Empresas de São Paulo, Fundação Getulio Vargas, São Paulo, 2019.

CAMARGO, Daniela Arguilar; HERMANY, Ricardo. Migração venezuelana e poder local em Roraima. Revista de Estudos Jurídicos UNESP, Franca, ano 22, n. 35, p. 229-251, jan./jun. 2018. Disponível em: https: / / ojs.franca.unesp.br/index.php/estudosjuridicosunesp/article/view/2608/2352. Acesso em: 3 jun. 2019. 
CAVALCANTI, Marilda C. O pós-ápice da migração haitiana no país em notícia recortada em portal de notícias: algumas notas sobre escolhas epistemológicas. DELTA, São Paulo, v. 35, n. 1, e2019350101, 2019.

CHISWICK, Barry R.; LEE, Yew Liang; MILLER, Paul W. The Determinants of the Geographic Concentration Among Immigrants: Application to Australia. IZA Discussion Paper No. 462, Bonn, Alemanha, mar. 2002. Disponível em: https://ssrn.com/abstract=306962. Acesso em: 05 fev. 2021.

CZAIKA, Mathias; HAAS, Hein de. The effectiveness of immigration policies. Population and Development Review, v. 39, n. 3, p. 487-508, 2013.

HAAS, Hein de; NATTER, Katharina. The determinants of migration policies. Does the political orientation of governments matter? DEMIG Project Paper 29, Working Papers, Paper 117, 2015.

HANSEN, Randall. Migration Policy. In: HAY, Colin; MENON, Anand (ed.). European politics. Oxford: Oxford University Press, 2007.

HOU, Feng. The Initial Destinations and Redistribution of Canada's Major Immigrant Groups: Changes over the Past Two Decades. Analytical Studies Branch Research Paper Series 254, Ottawa: Statistics Canada, 2005.

MAMED, Letícia Helena. Haitianos na Amazônia: a morfologia da imigração haitiana pelo Acre e o horizonte da inserção precarizada no Brasil. Revista do Centro de Estudos Rurais - RURIS, v. 10, n. 1, 2016.

MANTOVANI, Flávia. Após 1 ano, interiorização de venezuelanos alivia Roraima, mas falha na integração local. Folha de S.Paulo, 3 abr. 2019. Disponível em: https: / /www1.folha.uol.com.br/mundo/ 2019/04/interiorizacao-de-venezuelanos-alivia-roraima-mas-falha-na-integracao-local.shtml. Acesso em: 19 maio 2019.

NEWBOLD, K. Bruce. Spatial Distribution and Redistribution of Immigrants in the Metropolitan United States, 1980 and 1990. Economic Geography, v. 75, n. 3, p. 254-271, 1999.

PRESIDÊNCIA DA REPÚBLICA. Casa Civil. Operação Acolhida. Histórico. Brasília, dados publicados em 10 de maio de 2018, última modificação em 5 de abril de 2019. Disponível em: https://www.gov. br/acolhida/historico/. Acesso em: 15 jan. 2021.

PRESIDÊNCIA DA REPÚBLICA. Casa Civil. Ata da Reunião do Comitê Federal de Assistência Emergencial para Acolhimento a Pessoas em Situação de Vulnerabilidade decorrente de Fluxo Migratório provocado por Crise Humanitária. 
Brasília, 2018a. Disponível em: http: / /www.casacivil.gov.br/operacao-acolhida/documentos/ata-2areuniao-comite-federal-de-assistencia-emergencial. Acesso em: 19 maio 2019.

PRESIDÊNCIA DA REPÚBLICA. Casa Civil. Relatório Trimestral do Comitê Federal de Assistência Emergencial. Brasília, 2018b. Disponível em: http://www.casacivil.gov.br/operacao-acolhida/documentos/20180621_ relatorio-trimestral-final-consolidado.pdf. Acesso em: 19 maio 2019.

ROCHA, Gustavo do Vale; RIBEIRO, Natália Vilas Pinto. Fluxo migratório venezuelano no Brasil: análise e estratégias. Revista Jurídica da Presidência Brasília, v. 20 n. 122, out. 2018/jan. 2019, p. 541-563. http:/ / dx.doi.org/10.20499/2236-3645.RJP2018v20e122-1820

ROTHSTEIN, Bo; USLANER, Eric. All for All: Equality, Corruption, and Social Trust. World Politics, v. 58, n. 1, p. 41-72, 2005.

SAMPAIO, Cyntia; SILVA, João Carlos Jarochinski. O Brasil precisa de um plano para os venezuelanos que chegam. El País, Opinião, 11 abr. 2018. Disponível em: https: / / brasil.elpais.com/brasil/2018/04/10/ opinion/1523393064_479158.html. Acesso em: 21 maio 2019.

SIMÕES, Gustavo da Frota; CAVALCANTI, Leonardo; OLIVEIRA, Antônio Ribeiro de. Imigração venezuelana no Brasil: perfil sociodemográfico e laboral. In: KOECHLIN, José; EGUREN, Joaquín (ed.). El éxodo venezolano: entre el exilio y la emigración. Colección OBIMID. Lima: Universidad Antonio Ruiz de Montoya; Konrad Adenauer Stiftung; Organización Internacional para las Migraciones, 2018. v. 4. p. $115-134$.

TÜZÜN, Lilian Maria Tonella. An investigation of the strategy of interiorization of the Venezuelans refugees in Brazil. OPUS - International Journal of Society Researches, v. 8, n. 15, p. 1696-1715, 2018. doi: $10.26466 /$ opus. 451320 .

UEBEL, Roberto Rodolfo Georg; RÜCKERT, Aldomar Arnaldo. Haitianos no Rio Grande do Sul: panorama e perfil do fenômeno imigratório contemporâneo. Périplos: Revista de Pesquisa sobre Migrações, v. 1, n. 1, 2017.

XAVIER, Fernando César Costa. Migrações internacionais na Amazônia brasileira: impactos na política migratória e na política externa. 2012. 192 f. Tese (Doutorado em Relações Internacionais e Desenvolvimento Regional) - Programa de Pós-Graduação interinstitucional da Universidade de Brasília/FLACSOBrasil/UFRR, Brasília, 2012. 


\section{COMO CITAR ESTE ARTIGO:}

XAVIER, Fernando César Costa. A interiorização como um direito social universalizável. Revista Direito GV, v. 17 , n. 1, jan./abr. 2021, e2102. doi: http:// dx.doi.org/10.1590/2317-6172202102.

\section{Fernando César Costa Xavier}

Professor Associado do Instituto de CIÊNCIAS JuRÍdicAs dA Universidade Federal de Roraima (UFRR). Professor Doutor Nível I da Universidade Estadual de Roraima (UERR). DOUTOR EM RELAÇÕES INTERNACIONAIS PELA UNIVERSIDADE DE BRASÍLIA (UnB) E Doutorando em Sociologia E Direito PELA Universidade Federal Fluminense (UFF). CoORdenador do Projeto de PESQUisa “Direitos FundamentaIS, Constitucionalismo e a Migração Venezuelana”, cadastrado junto à Pró-Reitoria de

Pesquisa e Pós-graduação da Universidade Federal de RORAIMA (PRPPG/UFRR).

fxavier010lahotmail.com 